\title{
A INSTRUÇÃO EXPLÍCITA E SEUS EFEITOS NA PRODUÇÃO E NA PERCEPÇÃO DAS FRICATIVAS ANTERIORES DO PORTUGUÊS BRASILEIRO/L2 POR HISPANOFALANTES LATINO-AMERICANOS/L1
}

Rafael Alves de Oliveira Universidade Federal de Pernambuco

\section{RESUMO}

No português, as fricativas anteriores surdas e sonoras constituem-se como fonemas e ocupam posição de contraste (CAMARA JR, 1977). No espanhol, enquanto as fricativas surdas constituem-se como fonemas, as sonoras só aparecem na língua como alofones posicionais ou por assimilação de vozeamento (HUALDE, 2014). Este artigo tem como objetivo analisar as estratégias de pronúncia e investigar os efeitos da instrução fonética explícita na produção e na percepção das fricativas anteriores sonoras por hispanofalantes latinoamericanos aprendizes do português brasileiro. Os resultados, analisados com base nas teorias de percepção da fala em L2 (FLEGE, 1995; BEST, 1995; BEST; TYLER, 2007) e nas teorias dinamicistas sobre o desenvolvimento de L2 (LARSENFREEMAN, 1997; VERSPOOR, LOWIE, DE BOT, 2007), indicam, dentre outros aspectos, que a instrução explícita é uma ferramenta indispensável para o ensino da pronúncia em salas de Português como Língua Estrangeira.

PALAVRAS-CHAVE: Português como Língua Estrangeira. Hispanofalantes. Instrução Explícita. Fricativas Anteriores.

\section{Introdução}

Muito se tem discutido, atualmente, sobre a importância do ensi- 
no da pronúncia em sala da aula de língua estrangeira. No entanto, esse aspecto ainda tem recebido pouca atenção nas salas de aula de Português como Língua Estrangeira (PLE). Um estudo feito com materiais didáticos de PLE disponíveis no mercado aponta que a forma como a pronúncia tem sido abordada não é suficiente para minimizar essa lacuna (SILVEIRA; ROSSI, 2006). Isto porque, apesar de apresentarem e explicarem superficialmente algumas formas, os materiais não propõem exercícios fonéticos explícitos para que os aprendizes alcancem tais produções em termos articulatórios. Por outro lado, ironicamente, muitos estudos já revelaram que a instrução fonética explícita é uma aliada bastante eficaz para se alcançar uma pronúncia inteligível e com pouco sotaque (DERWING; MUNRO, 2005; LARSEN-FREEMAN, 2007).

Assim sendo, o presente estudo tem o objetivo de (1) descrever as estratégias de pronúncia empregadas por falantes nativos do espanhol latino-americano (ELA) na produção das fricativas anteriores do português brasileiro (PB) (/f,v,s, $\left., \int, 3 /\right)$; (2) investigar os efeitos da instrução fonética explícita na produção das fricativas anteriores e, ainda, (3) analisar as projeções da instrução na percepção do contraste de vozeamento das correspondentes homorgânicas surdas.

\section{Produção e Percepção da Fala em L2 e a Instru- ção Explícita: uma visão dinâmica}

Os modelos clássicos que tratam da percepção da fala em L2, como o Speech Learning Model (SLM) (FLEGE, 1995) e o Perceptual Assimilation Model (PAM) (BEST, 1995; BEST; TYLER, 2007), indicam que há uma tendência de aprendizes de uma L2 serem guiados pela língua materna (L1) sempre que se depararem com fonemas que não integram o seu sistema fonético-fonológico.

A principal premissa do SLM é mostrar que indivíduos adultos permanecem com a capacidade de diferenciação dos contrastes fonético-fonológicos ao longo do percurso de aprendizagem de uma L2, diferentemente do que propõe a Hipótese do Período Crítico. Segundo Flege (1995), a aprendizagem de L2 é baseada na capacidade de estabelecer distinção entre formas marcadas na L1. Assim, quanto maior for a "dissimilação" estabelecida para a formação de novas categorias na L2, melhor será a capacidade de percebê-las e articulá-las adequadamente. Por outro lado, os sons da L2 que forem foneticamente semelhantes e assimilados 
aos da L1 serão mais difíceis de serem percebidos e articulados, processo chamado de "classificação por equivalência". Além disso, o SLM reconhece que fatores como o tipo de instrução recebida, a motivação do indivíduo em aprender a L2 e o tipo de exposição à língua, por exemplo, podem influenciar no bom desempenho desses aprendizes, principalmente no que diz respeito à pronúncia.

No modelo de Best (1995) e Best e Tyler (2007), o pressuposto principal é de que os indivíduos recebem informação diretamente do meio em que vivem, através de sistemas integrados de percepção. Assim, as similaridades segmentais da L2 e o conjunto de propriedades da L1, em relação ao grau de constrição e ao modo de realização dos gestos, são determinantes para a [errônea] assimilação perceptiva dos fones da L2 à categoria da L1. Em casos em que há grande discrepância, os sons da L2 só poderão ser percebidos se existirem propriedade similares entre a L1 e a L2.

Assim, por levarem em consideração que diversos fatores interagem no processo de desenvolvimento de uma L2, o SLM e o PAM, expostos acima, podem ser considerados teorias dinamicistas de aquisição da linguagem, uma vez que destoam das primeiras abordagens sobre aquisição de L2, como a behaviorista e estruturalista, que julgavam as estratégias de pronúncia ${ }^{1}$ como meras "transferências" ou "erros" (LADO, 1957; CORDER, 1967), baseando-se unicamente no que está previsto nos quadros fonêmicos de duas línguas distintas em interação.

Uma visão dinamicista de linguagem trata a aquisição/desenvolvimento ${ }^{2}$ de L2 como um processo "dinâmico, complexo, não linear, caótico, imprevisível, sensível às condições iniciais, aberto, auto-organizado, sensível a feedback e adaptativo" (LARSEN-FREEMAN, 1997, p.142 [negrito nosso]). O processo é dinâmico porque muda com o passar do tempo e, ao mesmo tempo, complexo pois abrange um vasto número de agentes que interagem entre si e com outros agentes no ambiente. Conforme Veespor et al. (2007, p.64), “o sistema linguístico por si mesmo e o sistema linguístico individual são vistos como sistemas dinâmicos que interagem continuadamente com forças internas e externas e nunca são os mesmos em dois pontos diferentes no tempo", uma vez que o sistema toma como guia o que se costuma chamar de "estados atratores". Estados atratores são "subsistemas dinâmicos que costumam mover-se espontaneamente através de estados específicos, que são preferíveis, mas não previsíveis" (VEESPOR et al. 2007, p.65). Portanto, esses estados atratores 
fornecem momentos de estabilidade na interlíngua do aprendiz até que outro "atrator estranho" desestabilize o estado atrator anterior.

Um sistema dinâmico, como o processo de L2, nunca será o mesmo em dois pontos no tempo. Para Ellis (2006; 2008), o "estágio final limitado", que poderíamos associar ao conceito de fossilização, cunhado por Selinker e Lamendella (1978), é resultado de ciclos dinâmicos de uso, mudança, percepção e do aprendizado interativo com indivíduos das comunidades linguísticas. Sendo assim, no contexto naturalístico, altamente favorável à aprendizagem de L2, as estruturas linguísticas são facilmente afetadas pelo que denominou como "bloqueio" (blocking) e "ofuscamento" (overshadowing). O bloqueio é decorrente dos ofuscamentos que, por sua vez, são causados pelo "efeito de atenção seletiva". Esse último fator inibe as características mais proeminentes de um determinado som, impedindo-o, assim, de poder ser percebido sempre que aparecer. Segundo Ellis (2006, p. 178), "o bloqueio é resultado de uma automatização do aprendizado desatento [...] e pode ser penetrante e duradouro: uma vez que uma pista tenha sido bloqueada, os aprendizados sobre essa pista serão enfraquecidos".

Dessa forma, de acordo com autor, o aprendizado ${ }^{3}$ de L 2 pode acontecer de duas formas distintas: a primeira se dá no contexto naturalístico; a segunda pode ocorrer por meio de instrução explícita, foco na forma ou feedback corretivo. Contudo, como mesmo afirma o autor, o contexto naturalístico não impede que alguns detalhes passem despercebidos pelo aprendiz. Esses detalhes não percebidos favorecem a instrução explícita. Larsen-Freeman (2011, p. 58) indica que sem instrução explícita, o uso da língua pela maioria dos aprendizes adultos resulta num desenvolvimento limitado de recursos linguísticos. Segundo a autora, para ajudar o aprendiz de L2 a superar dificuldades e a galgar novos níveis de proficiência, a consciência e a atenção deste devem ser recrutadas através de uma instrução explícita, que precisa ser complementada com oportunidades para que esse aprendiz se utilize de seus próprios recursos linguísticos por meio de atividades psicologicamente autênticas.

É nessa direção que estão os trabalhos desenvolvidos por Stein (2011) e Silva (2008). A última autora descreve a importância de se reconhecer que o aprendiz adulto não é uma tabula rasa, mas que é com base nos gestos da L1 que o professor de L2 pode elaborar exercícios que ajudem o aprendiz a adaptar ponto e/ou modo de articulação e, assim, alcançar a produção adequada de determinado som na L2. Stein (2011) direciona seu estudo para a necessidade do conhecimento fonético 
acústico-articulatório por parte do professor de L2, para que, a partir das estratégias utilizadas pelo aprendiz na L2, elabore exercícios fonético-articulatórios que partam de movimentos mais simples (como a produção inadequada na L2 ou fones próximos ao fonema-alvo da L2 disponíveis na L1 do aprendiz) para atingir movimentos mais complexos (aqueles que não estão presentes na L1 do aprendiz).

\section{Metodologia}

Esta seção tem como objetivo descrever os procedimentos utilizados para coleta de dados de produção e de percepção das fricativas anteriores.

\subsection{Coleta de dados: testes de produção e de percepção}

O protocolo de coleta de dados foi aplicado a duas turmas experimentais, denominadas Turma de Controle (TC) e Turma de Intervenção (TI), e constituiu-se de leitura de 60 frases com palavras foneticamente balanceadas (tokens), em que /f, $, \mathrm{s}, \mathrm{s}, \mathrm{z}, \int, 3 /$ estivessem em posição de sílaba inicial ou medial, seguidos das sete vogais orais do PB, e de um teste de múltipla escola forçada (Multiple Forced Choice). Os dois testes foram aplicados antes, durante e depois da intervenção com os exercícios fonéticos. O Teste 1 foi aplicado com o intuito de verificarmos quais as dificuldades na pronúncia dos sons e analisarmos as principais estratégias empregadas pelos informantes hispanofalantes, tanto da TI quanto da TC. Os Testes 2 e 3 foram aplicados para investigarmos quais os avanços da instrução fonética da TI (também aplicado à TC). O quadro 1, abaixo, apresenta os códigos, o nível de proficiência, a nacionalidade, a idade e o sexo dos participantes desta pesquisa.

Quadro 1 - Códigos dos participantes da TC e da Tl.

\begin{tabular}{|l|l|l|l|l|}
\hline Participante & Nivel de Proficiência & Nacionalidade & Idade & Sexo \\
\hline TIMBAS & básico & colombiano & 26 & Masculino \\
\hline TIFBAS & básico & colombiana & 32 & Feminino \\
\hline TIMAVA & avançado & colombiano & 28 & Masculino \\
\hline TIFAVA & avançado & colombiana & 27 & Feminino \\
\hline TCMBAS & básico & hondurenho & 23 & Masculino \\
\hline TCFBAS & básico & cubana & 24 & Feminino \\
\hline TCMAVA & avançado & colombiano & 28 & Masculino \\
\hline TCFAVA & avançado & colombiana & 27 & Feminino \\
\hline
\end{tabular}

Fonte: 0 autor, baseado em Oliveira (2016).

As gravações ocorreram numa sala silenciosa e com pouco ruído com o auxílio de um gravador TASCAM DR-05 e um microfone uni- 
direcional YOGA HT-81. A inspeção acústica foi realizada por meio do software Praat (BOERSMA; WEENINK, 2006). Na análise espectrográfica, levamos em consideração a transição formântica entre a fricativa e a vogal (CV ou VCV). Assim, as fricativas surdas e sonoras foram identificadas tanto através de identificação (ou não) da barra de vozeamento, como pelo parâmetro de duração do ruído fricativo.

Os desvozeamentos parciais das fricativas sonoras serão tratados, aqui, como um processo dinâmico que faz parte do percurso de desenvolvimento de L2, diferentemente de como é visto quando ocorre na L1, "quando parece ser mais uma redução de esforço do que uma tentativa de vibração da glote, mesmo em casos de assimilação a uma consoante surda" (SMITH, 1997, p.198).

O teste auditivo-perceptivo de múltipla escolha forçada aplicado foi construído via script no Praat. Consistiu-se na seleção forçada de apenas uma palavra do par mínimo exposto, do tipo "zelo - selo", a partir de um único estímulo auditivo recebido.

\subsection{Os exercícios fonéticos aplicados à turma de intervenção}

Os exercícios fonéticos foram construídos em etapas que visavam a conscientização articulatória e ortográfica e foram divididos da seguinte forma:

1. Instrução articulatória e perceptiva: (a) instruir os participantes sobre a diferença entre sons surdos e sonoros, com o exemplo do [m], como no PB e no espanhol; (b) instruir sobre articulação dos sons fricativos e sua oposição de vozeamento; (c) realizar tarefa de percepção tátil e produção de onomatopeias como a de um "azoino" de uma abelha, por exemplo.

2. Instrução ortográfica: instruir os participantes sobre as regras fonotáticas do PB para os contextos silábicos em que /f, v/, /s, z/ ou / /, 3/ aparecem.

3. Exercícios práticos: viabilizar aos participantes a oportunidade de pôr em prática os exercícios realizados nas etapas (1) e (2), primeiramente com leitura de palavras e, em seguida, frases ${ }^{4}$ com palavras em que os sons aparecessem em posição de início de sílaba. 


\section{Descrição e discussão dos resultados}

Nesta seção serão apresentados e discutidos os resultados obtidos por meio da aplicação do protocolo explicitado na seção anterior. Num primeiro momento, serão expostas as principais estratégias de pronúncia empregadas pelos participantes da pesquisa (subseção 4.1); num segundo momento, apresentaremos os resultados obtidos pós-instrução explícita (subseção 4.2), tanto para produção quanto para percepção.

\subsection{Estratégias de pronúncia}

A primeira tarefa de leitura de frases, coletada em ambas as turmas, permitiu-nos comprovar, por meio de inspeção acústica, as seguintes estratégias utilizadas para as fricativas anteriores sonoras:

Estratégias de pronúncia empregadas para $/ \mathrm{v} /$ :

No espanhol, o fonema / $\mathrm{b} /$ é representado na ortografia pelas letras «b» e «v» (e.g. boca [b]oca - vaca [b]aca), e, dependendo do contexto de sonoridade em que vier precedido e antecedido na sílaba, pode ocorrer alofonicamente como oclusivo bilabial surdo [b] ou como fricativo bilabial sonoro $[\beta]$. O alofone oclusivo aparecerá quando antecedido por pausa ou por um segmento nasal (am[b]os), enquanto que o alofone fricativo aparecerá quando vier seguido por uma vogal, entre duas vogais, em interior de sílaba seguida por consoante ou quando seguido por uma consoante sonora (HUALDE, 2014); ou seja, em tese, [ $[\beta]$ pode ocorrer em contextos silábicos bem mais amplos que [b].

Nos dados averiguados, foi possível identificar as seguintes substituições para [v]: fricativa labiodental surda: [f]; fricativa bilabial sonora: $[\beta]$; oclusiva bilabial sonora: $[\mathrm{b}]$.

A estratégia mais produtiva utilizada pelos hispanofalantes da TI foi o emprego de [ $\beta]$, alofone posicional do espanhol, como mostra a Figura 1. A utilização de [ $\beta]$ como estratégia em "o envelope" atende à hipótese de que alofones da L1 são utilizados como estratégias de pronúncia na L2, já que o esperado para o contexto seria o emprego de [b], isto é, uma simples transferência de regras fonotáticas da L1 para a L2, já que o grafema «V» ante uma vogal nasal implicaria o emprego da oclusiva, e não de uma fricativa bilabial, como ocorreu.

Os sons de [v] e [ $[\beta]$ possuem traços fonéticos finos que obviamente podem levar ao reconhecimento do aprendiz hispanofalante como não 
nativo. Esse tipo de estratégia é bastante produtivo nos estágios iniciais, a nosso ver, pois reforça a ideia de que esses aprendizes substituem os sons da L2 pelos que possuem modo de articulação mais próximo aos da L1.

Figura 1 - Estratégia de pronúncia empregada por um hispanofalante para fricativa labiodental sonora.

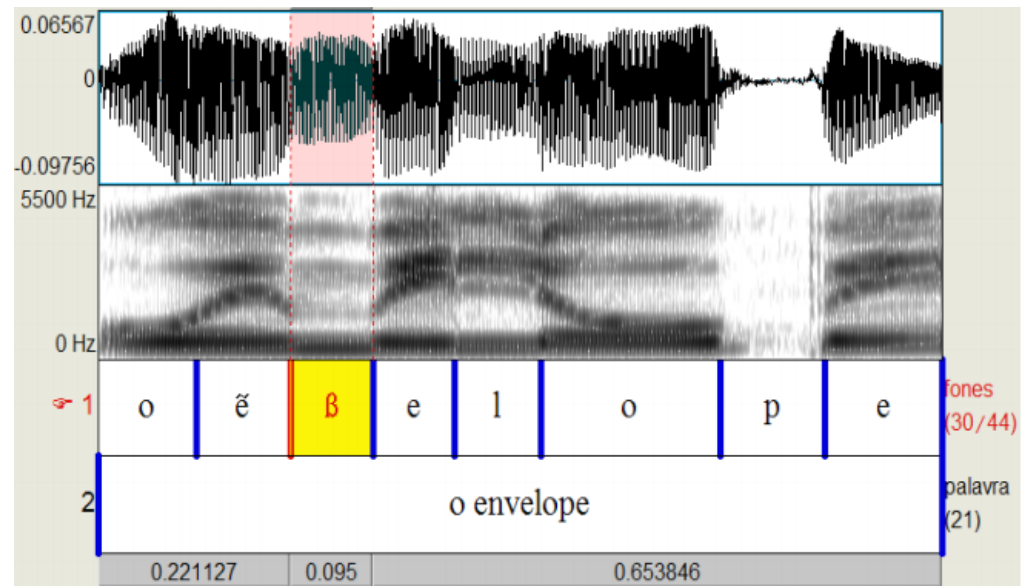

Fonte: Oliveira (2016).

Outras estratégias bastante produtivas na língua foram as já mencionadas [f] e [b]. O gráfico 1 mostra as produções dos 8 informantes da pesquisa e indica que há uma tendência de os aprendizes abandonarem estratégias de pronúncia que não são bons exemplos na L2 ao longo do processo de aprendizagem, como sugerem Flege (1995) e Best (1995). Note-se que aprendizes de nível básico e de nível avançado não necessariamente se comportam de maneiras distintas em relação à seleção de um fone a produzir, e nem, inclusive, utilizam-se das mesmas estratégias. Outra observação que temos a fazer em relação a isso consiste no fato de os aprendizes de nível básico terem produzido com maior frequência [b] do que os aprendizes de nível avançado, com exceção de TIMBAs. Este é um indício de que os aprendizes de nível básico, assim como os de nível avançado, tendem a abandonar esse tipo de estratégia ao perceberem que [b] é um exemplo que está totalmente fora da categoria da L2 (BEST, 1995). O informante TImBAs parece ter percebido melhor que [b] não era 
categoria para ser empregada para [v], tanto que, notadamente, sequer utilizou-se dessa estratégia para o fone em questão, optando muito mais por $[\mathrm{v}]$ ou $\left[\mathrm{v}^{*}\right]^{5}$ e $[\beta]$. A quantidade de vezes em que cada indivíduo empregou algum tipo de estratégia e a diversidade de substituições utilizadas, independentemente do nível de proficiência, revela a não linearidade do processo de aquisição de L2, uma vez que as trocas não são totalmente previsíveis.

Gráfico 1 - Estratégias de pronúncia empregadas para fricativa labiodental sonora pelos informantes da Tl e da TC.

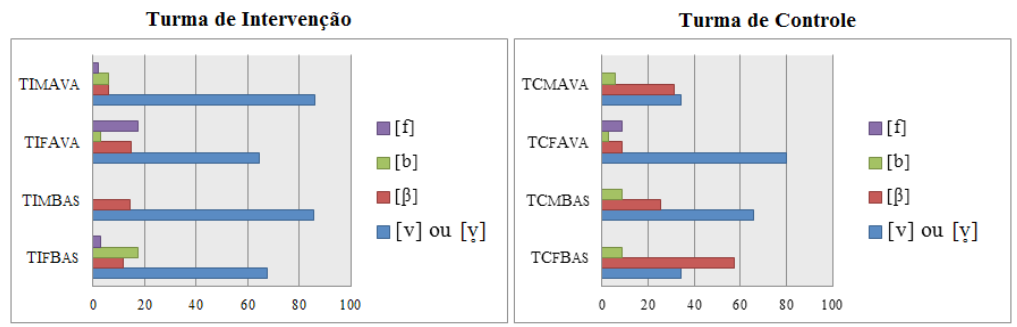

Fonte: 0 autor, com base em Oliveira (2016).

(b) Estratégias de pronúncia empregadas para /z/:

$\mathrm{O}$ fonema /s/, no espanhol, possui dois alofones, [s] e [z], que não têm função distintiva. [z], no espanhol, acontece apenas em contextos limitados de alta sonoridade por assimilação (HUALDE, 2014). Assim, é extremamente comum que o falante nativo de espanhol, que está acostumado apenas ao fonema $/ \mathrm{s} / \mathrm{com}$ duas variantes, tenha dificuldades de perceber e de produzir [z] em contextos em que é necessário o emprego de vozeamento, como no português, no inglês ou no francês, por exemplo. Esse processo pode ser explicado pelo que Flege (1995) denominou como "classificação por equivalência". A formação de uma nova categoria fonética e fonológica para / z/ é bloqueada e passa a ser processada apenas como uma única categoria perceptiva ligada ao espanhol (L1) e ao português (L2), que é [s]. O desvozeamento total foi encontrado nos dados de todos os informantes, independentemente do nível de proficiência. Esse tipo de substituição foi indicado como a produção de [s]. 
Figura 2 - Estratégia de pronúncia empregada por um hispanofalante para a fricativa alveolar sonora.

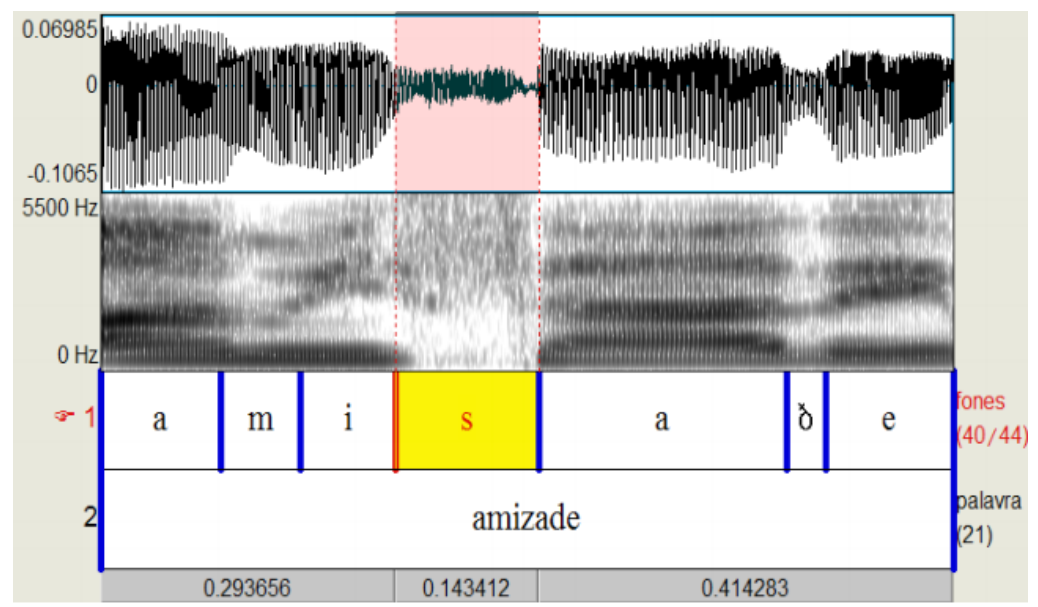

Fonte: Oliveira (2016).

No Gráfico 2, contudo, é possível notar que aprendizes do nível avançado tendem ao emprego de vozeamento, o que mostra uma recategorização que está começando a se estabelecer em termos acústico-perceptivos. A motivação em aprender a língua e o estabelecimento de hábitos de conversação em língua portuguesa podem ajudar o aprendiz a perceber e empregar o vozeamento para essa consoante. A variedade do espanhol também pode ter implicações nos usos e escolhas linguísticas que esses informantes fazem. Isso talvez explique porque os informantes da TI, todos colombianos, empregaram vozeamento em [z], e os informantes da TC, não (ver Quadro 1). 
Gráfico 2 - Estratégias de pronúncia empregadas para fricativa alveolar sonora pelos informantes da TI e da TC.

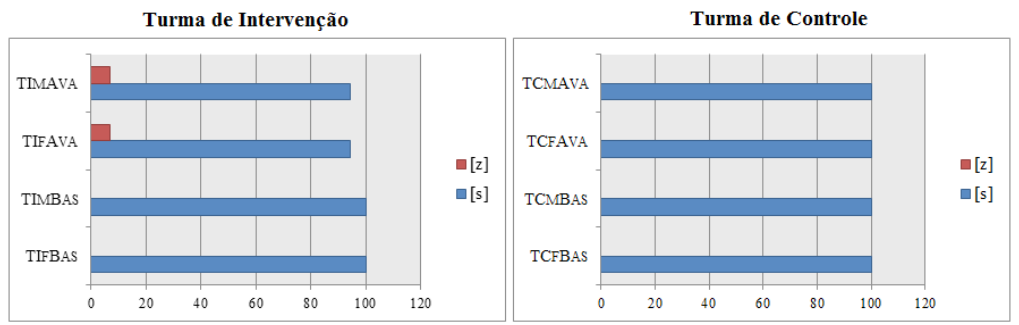

Fonte: 0 autor, com base em Oliveira (2016)

(c) Estratégias de pronúncia empregadas para /z/:

No que se refere ao emprego de estratégias de pronúncia para /3/ foi bastante produtiva. No espanhol falado na América Latina, tanto [3] quanto [S] são alofones, sistematicamente encontrados na região do Plata, que compreende partes da Argentina ${ }^{6}$ e do Uruguai. A pronúncia de [3] para os grafemas «ll» e «y» é chamado de žeísmo ou yeísmo rehilado. No espanhol colombiano, país de origem dos informantes da TI, parece acontecer o mesmo (MONTES GIRALDO, 1982).

$\mathrm{Na}$ análise dos dados, constatamos as seguintes estratégias: fricativa alveopalatal surda, [S]; africada alveopalatal sonora, [d3]; fricativa velar sonora, [y]; aproximante palatal sonora [j]; oclusiva velar sonora, [g].

No que diz respeito às produções mais realizadas, há uma diferença bastante clara entre os informantes de nível básico e os de nível avançado. Enquanto estes preferem [3], aqueles optam bem mais por [d3], com destaque para TIMBAS. Isso mostra que, à medida que interagem oralmente na L2, os aprendizes abandonam [d3] e implementam [3] com maior frequência. Para a palavra "pajé", na Figura 3, por exemplo, seria previsto, pelo contexto, [Y] e não [d3], nessa variedade do espanhol. Logo, esse tipo de substituição não pode ser visto como uma simples troca de um som da L2 por um som da L1, mas sim como uma substituição intencional para aproximar ponto e modo de articulação de [3]. Este é também mais um exemplo do processo adaptativo da interlíngua do falante, que está estabelecendo cognitiva e articulatoriamente [3] como uma única categoria fonética e fonológica, como sugere Best e Tyler (2007). Esse fato é evidenciado pelo alto desempenho dos informantes da TI na produção de [3] em relação às demais estratégias, como mostra o Gráfico 3. 
Figura 3 - Estratégia de pronúncia empregada por um hispanofalante para fricativa alveopalatal sonora.

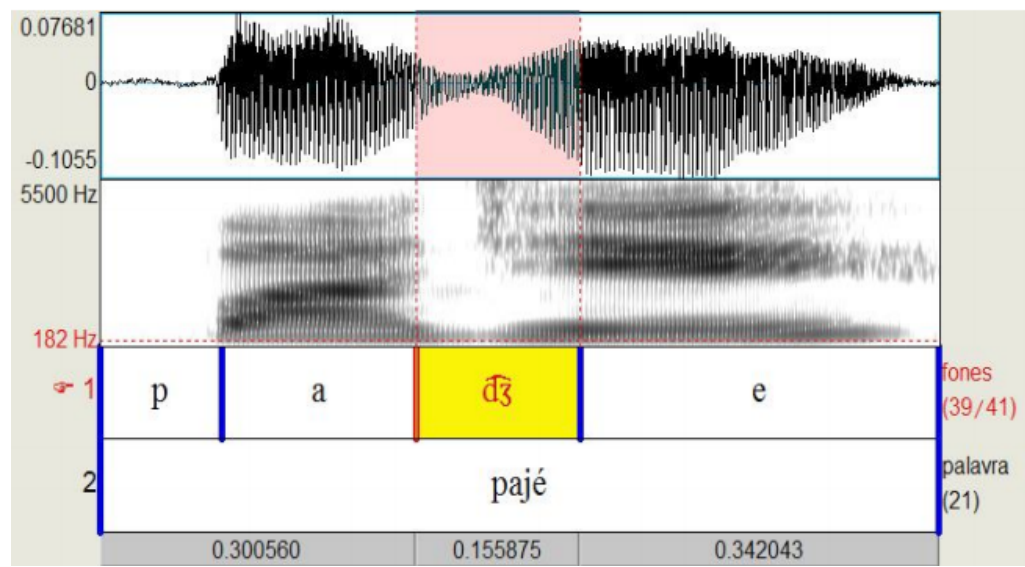

Fonte: Oliveira (2016).

O desvozeamento total de [3], representado como [ $\left.\int\right]$, também nos permite sugerir que houve uma tentativa de aproximação dos gestos articulatórios para sua produção, com exceção da vibração das pregas vocais. [S] foi utilizado muito mais pelos informantes de nível avançado do que pelos de nível básico. Apesar da troca causar problemas na comunicação, esse tipo de estratégia também pode ser considerado como um processo dinâmico.

[४] foi muito pouco aproveitado pelos informantes, sendo usado exclusivamente por TIFBAS. [४] configura-se como alofone de /g/, que ocorre, no espanhol, antes de pausa ou de consoante nasal. Como afirmam D'Introno

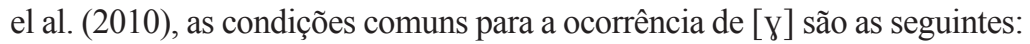
posição intervocálica, início de palavra seguida por uma vogal e final de sílaba. Como podemos observar na Figura 4, o emprego de $[\gamma]$ na leitura da palavra "gíria" pode ser consequência negativa da variável ortografia. Contudo, [४] foi utilizado poucas vezes pelos informantes de nível básico da TI e da TC, sendo deixado de lado pelos de nível avançado. Para esse caso, permitimo-nos mencionar um dos parâmetros propostos por Best (1995), de que esse fone foi considerado um exemplo claro de desvio da categoria de [3] no contexto linguístico da L2. Os dados indicam que os aprendizes de nível avançado já conseguem fazer a dissimilação desse fone na L1 e na L2. 
Figura 4 - Estratégia de pronúncia empregada por um hispanofalante para fricativa alveopalatal sonora com possivel interferência negativa da variável ortografia.

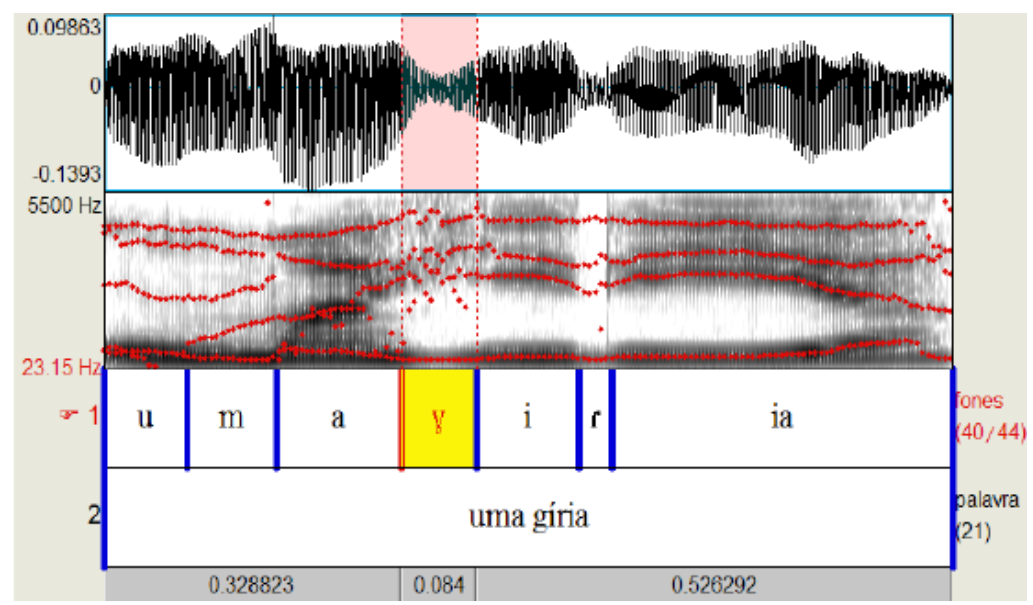

Fonte: Oliveira (2016)

Como aponta o Gráfico 3, [j] também foi estratégia usada apenas por TCMAvA, de nível avançado e nacionalidade cubana. D'Introno et al. (2010) e Hualde (2014) indicam que / $\mathrm{j} /$, representado ortograficamente

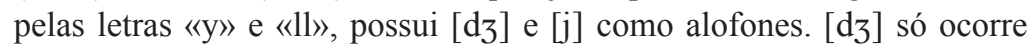
antecedido por consoante nasal. O emprego insistente de [j] por TCMAvA parece não ser efeito da variável ortografia. Na palavra «lajota», do português, por exemplo, não há regra que estabeleça para ambas as línguas o emprego de uma aproximante/fricativa palatal $^{7}$ nesse contexto linguístico. Mais uma vez, constata-se, aqui, uma instabilidade na interlíngua do falante, que, de tão específica, não é utilizada pelos demais participantes da pesquisa.

Com o mesmo viés explanatório mencionaremos o emprego solitário de [g] na palavra "vergê" (produzida como [vege], em vez de [veh"ge]). Esta estratégia, utilizada uma única vez pela informante TCFAvA, mostra-se como um exemplo claro de desvio da interlíngua, pois o emprego de [g] não seria possível nem no português, em que se utilizaria um [3], nem na sua língua materna, o espanhol, em que seria aceitável uma sobreposição direta por [Y], por exemplo. Nesse caso, sugerimos que a ortografia influenciou negativamente esse tipo de estratégia, uma vez que a letra «g», nesse contexto, não confere com o padrão fonotático das línguas. 
Gráfico 3 - Estratégias de pronúncia empregadas para fricativa alveopalatal sonora pelos informantes da TI e da TC.

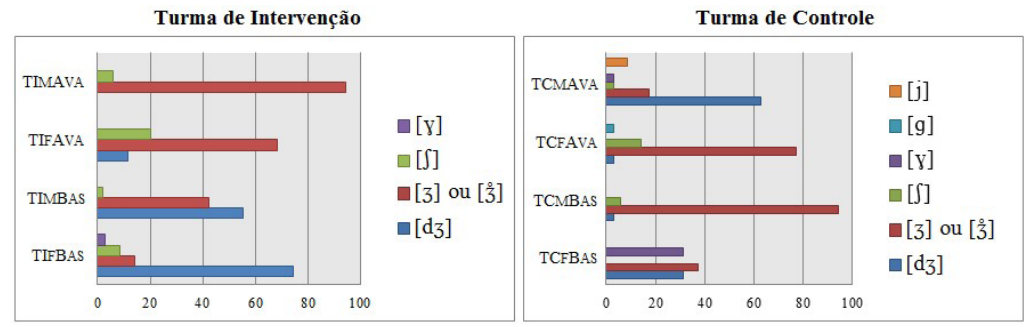

Fonte: 0 autor, com base em Oliveira (2016).

Em suma, apresentamos algumas das estratégias de pronúncia utilizadas pelos informantes da TI e da TC, com o intuito de mostrar o processo de desenvolvimento de L2 sem a intervenção fonética explícita, em ambas as turmas. A seguir, apresentaremos os resultados obtidos pela TI comparados aos da TC.

\section{à $\mathrm{Tl}$}

\subsection{Resultados da Instrução Fonética Explícita aplicada}

Esta seção tem como objetivo apresentar um quantitativo das estratégias de pronúncia empregas por cada um dos participantes da TI, bem como mostrar evidências estatísticas que indicam efeitos positivos da instrução fonética explícita aplicada.

\subsubsection{Teste de produção: descrição individual da Tl e análise comparativa com a TC}

No quadro 2, abaixo, avaliando-se as coletas 2 e 3, a informante TIFBAS não apresentou muitas dificuldades em implementar foneticamente [v] em suas produções, o que justifica os números apresentados, comparando-se os testes 1 e 3. Já para o emprego de vozeamento em [3], nos primeiros dados coletados, a informante apresentou desvozeamento total para os 35 tokens. Comparando-se os testes pré- e pós-instrução, houve avanço significativo em relação ao emprego do traço de sonoridade, produzido em $85,2 \%$ das realizações. Para [3], a informante, que costumava empregar [d3] em vez de [3], em cerca de 74,2\% das produções no pré-teste, passou a utilizar [ $\left.\mathrm{d}_{3}\right]$ em apenas $17,2 \%$ das realizações no pós-teste. 
O informante TIMBAS foi o único da turma de intervenção que não apresentou um número variado de estratégias para /v/. Durante os oito meses residindo no Brasil, TIMBAS parece já ter categorizado foneticamente [v] em sua interlíngua, deixando, ao longo das aulas de instrução fonética, [b] de lado. Para /z/, já no teste 2, o informante apresentou $94,2 \%$ de produções com vozeamento, seja parcial ou total, aumentando, ainda, no teste 3 realizado, para 97, 1\% dos 35 tokens. Em relação à substituição de [3] por [d3], TImBAs passou a produzir [3] de modo adequado na L2 em 100\% dos tokens, no pós-teste.

Quadro 2 - Resumo das estratégias de pronúncia empregadas pelos informantes da TI.

\begin{tabular}{|c|c|c|c|c|}
\hline $\begin{array}{l}\text { Cód. } \\
\text { Inf. }\end{array}$ & $(\%)$ & $\begin{array}{l}\text { Teste } 1 \text { (Pré- } \\
\text { intervenção) }\end{array}$ & $\begin{array}{l}\text { Teste } 2 \text { (Pós- } \\
\text { intervencão) }\end{array}$ & $\begin{array}{l}\text { Teste } 3 \text { (Pós- } \\
\text { intervencão) }\end{array}$ \\
\hline \multirow[t]{3}{*}{ TIFBAS } & $\begin{array}{l}\text { W/, 35 } \\
\text { tokens }\end{array}$ & $\begin{array}{l}\text { [v] } 67,7 \\
\text { [b] } 17,6 \\
\text { [ß] } 11,8 \\
\text { [f] } 2,9\end{array}$ & $\begin{array}{l}\text { [v] } 91,1 \\
{[\mathrm{~b}] 2,9} \\
{[\beta] 5,8}\end{array}$ & $\begin{array}{l}\text { [v] } 94,1 \\
{[B] 5,9}\end{array}$ \\
\hline & $\begin{array}{l}z /, 34 \\
\text { tokens }\end{array}$ & [s] $100 \%$ & $\begin{array}{l}8[z] 76,4 \\
{[\mathrm{~s}] 23,6}\end{array}$ & $\begin{array}{l}8[z] 85,2 \\
{[\mathrm{~s}] 14,8}\end{array}$ \\
\hline & $\begin{array}{l}/ \mathcal{J}, 35 \\
\text { tokens }\end{array}$ & $\begin{array}{l}\text { [d3] } 74,2 \\
\text { [3] } 14,2 \\
{\left[\int\right] 8,5} \\
{[\mathrm{Y}] 2,8}\end{array}$ & $\begin{array}{l}{[3] 88,2} \\
{\left[d_{3}\right] 11,8}\end{array}$ & $\begin{array}{l}{[3] 82,8} \\
{\left[d_{3}\right] 17,2}\end{array}$ \\
\hline \multirow[t]{3}{*}{ TIMBAS } & $\begin{array}{l}\text { W/, } 35 \\
\text { tokens }\end{array}$ & $\begin{array}{l}{ }^{8} \text { [v] } 85,8 \\
\text { [b] } 14,2\end{array}$ & ${ }^{8}[\mathrm{v}] 100$ & ${ }^{8}[\mathrm{v}] 100$ \\
\hline & $\begin{array}{l}/ z, 34 \\
\text { tokens }\end{array}$ & [s] 100 & $\begin{array}{l}8[z] 94,2 \\
{[s] 5,8}\end{array}$ & $\begin{array}{l}8[z] 97,1 \\
{[s] 2,9}\end{array}$ \\
\hline & $\begin{array}{l}/ / J^{\prime}, 35 \\
\text { tokens }\end{array}$ & $\begin{array}{l}{\left[d_{3}\right] 55,5} \\
*[3] 44,5\end{array}$ & $\begin{array}{l}\text { '[3] } 91,5 \\
\text { [d3] } 8,5\end{array}$ & ${ }^{8}[3] 100$ \\
\hline \multirow[t]{3}{*}{ TIFAVA } & $\begin{array}{l}W /, 35 \\
\text { tokens }\end{array}$ & $\begin{array}{l}{ }^{8} \text { [v] } 64,7 \\
\text { [f] } 17,6 \\
\text { [B] } 14,8 \\
\text { [b] } 2,9\end{array}$ & $\begin{array}{l}\text { [v] } 47,1 \\
\text { [B] } 44,2 \\
\text { [b] } 5,8 \\
\text { [f] } 2,9\end{array}$ & $\begin{array}{l}{ }^{8}[\mathrm{v}] 73,7 \\
\text { [B] } 17,6 \\
\text { [b] } 5,8 \\
\text { [f] } 2,9\end{array}$ \\
\hline & $\begin{array}{l}\mathcal{Z} / 34 \\
\text { tokens }\end{array}$ & $\begin{array}{l}{[\mathrm{s}] 94,2} \\
{[z] 5,8}\end{array}$ & $\begin{array}{l}8[z] 70,6 \\
\text { [s] } 29,4\end{array}$ & $\begin{array}{l}{ }^{*}[z] 94,2 \\
{[s] 5,8}\end{array}$ \\
\hline & $\begin{array}{l}\text { / } / 3 /, 35 \\
\text { tokens }\end{array}$ & $\begin{array}{l}{[3] 68,5} \\
{\left[d_{3}\right] 11,5} \\
{[J] 20}\end{array}$ & $\begin{array}{l}\text { [3] } 97,2 \\
\text { [S] } 2,8\end{array}$ & ${ }^{*}[3] 100$ \\
\hline \multirow[t]{3}{*}{ TIMAVA } & $\begin{array}{l}W /, 35 \\
\text { tokens }\end{array}$ & $\begin{array}{l}{ }^{8} \text { [v] } 86,3 \\
\text { [b] } 5,8 \\
\text { [ß] } 5,8 \\
\text { [f] } 2,1\end{array}$ & $\begin{array}{l}\text { 8[v] } 97,2 \\
{[\beta] 2,8}\end{array}$ & ${ }^{8}$ [v] 100 \\
\hline & $\begin{array}{l}z /, 34 \\
\text { tokens }\end{array}$ & $\begin{array}{l}{[\mathrm{s}] 94,2} \\
{ }^{*}[z] 5,8\end{array}$ & $\begin{array}{l}{ }^{8}[z] 58,9 \\
{[\mathrm{~s}] 41,1}\end{array}$ & $\begin{array}{l}8[z] 94,2 \\
{[s] 5,8}\end{array}$ \\
\hline & $\begin{array}{l}\text { l/Jens } \\
\text { tokens }\end{array}$ & $\begin{array}{l}{ }^{8}[3] 94,5 \\
\text { [J] } 5,7\end{array}$ & $\begin{array}{l}3[3] 97,2 \\
\text { [J] } 2,8\end{array}$ & ${ }^{8}[3] 100$ \\
\hline
\end{tabular}

Obs.: Os fones que possuem asterisco $\left({ }^{*}\right)$ incluem casos de desvozeamento parcial. Fonte: 0 autor baseado em Oliveira (2016). 
De todos os participantes da TI, TIFAva foi a que mais teve dificuldade no emprego fonético e fonológico adequado de $/ \mathrm{v} /$. Como se pode notar no quadro 2, a diferença entre o teste 1 e o teste 3 aplicados é pouco expressiva se comparados aos dados dos demais participantes, inclusive dos de nível básico. Podemos considerar que os progressos e as diferenças entre os teste 1 e 2 se dão, sobretudo, pelo abandono de estratégias como [f] (utilizado expressivamente no Teste 1) para o uso significativo de $[\beta]$. Isso pode ser justificado porque [ $\beta]$ é uma categoria com traços articulatórios finos (que pode apresentar mostrar vários graus de constrição) semelhantes aos de $[\mathrm{v}]$, mostrando-se como uma estratégia muito mais aceita, principalmente considerando o traço de sonoridade presente em [ $[\beta] \mathrm{e}$ ausente em [f]. Nesse sentido, a instrução fonética forneceu um novo parâmetro acústico para nortear o uso de estratégias mais adequadas na L2. Como tratamos aqui de um processo contínuo, acreditamos ser bastante provável que o uso desse tipo de estratégia seja um primeiro passo para, gradativamente, um som da L1 ser substituído por um da L2. Ainda com relação à labiodental sonora, os dados indicam a ligeira queda do uso de [v] entre os Testes 1 e 2, que, em nossa interpretação, refletem a instabilidade da interlíngua logo após a instrução explícita. Por uma tendência da interlíngua à auto-organização, essa estabilidade parece ir aos poucos se readaptando, comparando-se o Teste 2 e o 3 . Com relação ao emprego de vozeamento para a fricativa alveolar sonora, o que os dados do pré-teste indicam é uma leve tendência ao emprego do traço de sonoridade $(5,8 \%)$, que, no Teste 3, estabelece-se em 94,5\% das realizações. Quanto ao uso da alveopalatal sonora, a informante o realizou adequadamente em 100\% dos tokens apresentados, deixando de lado estratégias que ocorriam frequentemente em sua interlíngua, como [d3] ou [S].

$\mathrm{O}$ informante TImAva produziu [v] com bastante frequência no Teste 1, embora ainda tenha se utilizado de estratégias como $[\beta] \mathrm{e}[\mathrm{b}]$. Após as intervenções, passou realizar adequadamente a fricativa labiodental sonora em 100\% dos tokens. Para /z/, assim como a informante de nível avançado, TifAva, TImAva empregou vozeamento, no pré-teste, em $5,8 \%$ dos tokens apresentados. No pós-teste, esse número subiu expressivamente para $94,2 \%$ de realizações de vozeamentos parcial ou total em [z]. O emprego adequado de $/ 3 /$ foi uma dificuldade para o informante desde a aplicação do Teste 1. Isso se comprova, inclusive, pelo número reduzido (comparado aos demais) de estratégias de pronúncia para o som em questão. Os dados que já eram de 94,7\%, no pré-teste, passaram a 
$100 \%$ de realizações adequadas para [3].

Assim, ao submetermos os dados a um Teste-t pareado, com vistas a avaliar os efeitos da instrução fonética explícita aplicada à TI em relação à TC, comparando os Testes 1 e 3 e considerando $p<0,05$, obtivemos os seguintes resultados:

para /v/ o índice de acertos foi estatisticamente significativo $(p=0,0237)$ para a TI, mas não para a TC $(\mathrm{p}=0,167)$;

para $/ z /$ o índice de acerto foi estatisticamente significativo $(p=0,003)$ para a TI, mas não para a TC $(\mathrm{p}=0,391)$;

para /3/ o índice de acertos não foi estatisticamente significativo nem para a TI $(p=0,062)$, nem para a TC $(\mathrm{p}=0,215)$.

\subsubsection{Resultados dos testes auditivo-perceptivos}

Os resultados dos testes auditivo-perceptivos aplicados e descritos no capítulo 3 foram submetidos a um Teste-t pareado, a fim de se investigar as projeções da instrução fonética explícita na percepção dos sons fricativos anteriores em posição de contraste no português. Os resultados, comparando-se a TI e a TC, mostraram que:

a oposição em /f, $/$ e $/ \int, 3 /$ não se mostrou significativa nem na TI (/f,v/: $p=0,1400 ; / \mathrm{s} / 3 /: \mathrm{p}=0,3407)$ nem na TC (/f,v/: $p=0,3910 ; / \mathrm{S} / 3 /$ : $\mathrm{p}=0,0905)$;

o contraste entre $/ \mathrm{s}, \mathrm{z} /$ foi significativo estatisticamente apenas na TI $(\mathrm{p}=0,0003)$.

Os resultados estatisticamente significativos para o contraste entre /s,Z/ mostram que o foco da dificuldade de emprego de vozeamento está na percepção ainda não acurada dos hispanofalantes. Sobre esse aspecto, podemos constatar uma sincronia entre produção e percepção no desenvolvimento de L2, já que uma forma ainda não percebida não pôde ser produzida. Os números negativos para os contrastes $/ \mathrm{f}, \mathrm{v} / \mathrm{e} / \int, 3 /$ indicam que os informantes não tiveram dificuldades em perceber a troca do traço de sonoridade. Assim, embora esses sons não estabeleçam oposição no espanhol, eles ocorrem com muito mais frequência por serem alofones posicionais, o que permite que esses sons, mesmo em posição de contraste, sejam melhor percebidos. Por exemplo, se de uma lado [ $\beta]$ se assemelha acústico-articulatoriamente ao som-alvo [v], [d3] também parece guiar o aprendiz hispanofalante do português em direção a [3]. Nesses casos, os alofones da L1 se revelam como guias, tanto na produção quanto na percepção, no processo de desenvolvimento da L2. 
Em se tratando dos reflexos da instrução explícita nesses resultados, fica bastante evidente que a instrução explícita favorece a percepção do contraste de vozeamento, principalmente levando-se em consideração os resultados obtidos para as fricativas alveolares.

\section{Conclusão}

Guiados pelas proposições de Best (1995) e Flege (1995), bem como orientados pela noção de língua enquanto sistema dinâmico, adaptativo e complexo (LARSEN-FREEMAN, 1997; 2011; ELLIS, 2006; 2008), que preza pela a instrução fonética explícita, constatamos que:

os alofones da L1 são utilizados como estratégia para produção e para percepção das consoantes da L2;

os exercícios fonéticos aplicados mostraram-se estatisticamente significativos na produção, uma vez que os índices para o valor de $p$ foram inferiores a 0,05 ;

a percepção da oposição de vozeamento entre surdas e sonoras também foi favorecida após a aplicação do exercícios explícitos.

Esta pesquisa mostrou que, mesmo em contexto naturalístico, os hispanofalantes ainda sentem dificuldade em perceber alguns detalhes fonético-fonológicos do português, como a oposição e o emprego de vozeamento para as fricativas anteriores. Para isso, utilizamos exercícios fonéticos explícitos como forma de minimizar o bloqueio que existe nesse contexto de uso, como prevê a literatura (ELLIS, 2006; 2008; LARSEN-FREEMAN, 1997, 2011). Como previsto, os resultados foram positivos para a instrução explícita aplicada de forma sistemática e com base nas estratégias de pronúncia que esses aprendizes já utilizavam. Logo, mesmo com poucos minutos de intervenção dedicados em sala de aula, o ensino explícito da pronúncia mostra-se como ferramenta essencial para o professor de língua estrangeira, e principalmente para o de PLE. 


\section{THE EXPLICIT INSTRUCTION AND ITS EFFECTS IN PRODUCTION AND PERCEPTION OF BRAZILIAN PORTUGUESE ANTERIOR FRICATIVES BY LATIN- -AMERICAN SPANISH SPEAKERS}

\section{ABSTRACT}

In Portuguese, voiceless and voiced anterior fricatives constitute phonemes and can contrast (CAMARA JR, 1977). In Spanish, while voiceless fricatives form phonemes, voiced fricatives only appear in this language or as positional allophones or in cases of voicing assimilation (HUALDE, 2014). This research aims to analyze the pronouncing strategies and to investigate the effects of phonetics explicit instruction in production and perception of voiced anterior fricatives by Latin-American Spanish speakers learners of Brazilian Portuguese. The results indicate, based on Theories of L2 Speech Perception (FLEGE, 1995; BEST, 1995; BEST; TYLER, 2007) and on a dynamical view of L2 development (LARSEN-FREEMAN, 1997; VERSPOOR, LOWIE, DE BOT, 2007), among other aspects, that explicit instruction is, surely, an indispensable tool for pronouncing teaching in Portuguese as a Foreign Language classes.

KEYWORDS: Portuguese as a Foreign Language. Spanish speakers. Explicit instruction. Anterior fricatives.

\section{REFERÊNCIAS}

BEST, C. T. A direct realist view of cross-language speech perception. In: STRANGE, W. (Ed.), Speech perception and linguistic experience: issues in cross-language research. Timonium, MD: York Press, 1995. p. 171-204.

BEST, C.; TYLER M. Nonnative and second-language speech perception: Commonalities and complementarities. In: BOHN, O-S.; MUNRO, M.J., Eds., Language Experience in Second language Speech Learning: In honor of James Emil Flege. Amsterdam: John Benjamins, 2007. p. 13-34. 
BOERSMA, P.; WEENINK, D. Praat: doing phonetics by computer, 2006-2015. Versão 5.4.22. Disponível em: <http://www.praat.org/> . Acesso em: 15 ago. 2015. CAMARA JR., J. M. Para o estudo da fonêmica portuguesa. Rio de Janeiro: Padrão Editora, 1977.

CORDER, S. P. The significance of learner errors. International Review of Applied Linguistics, v. 5, n. 4, 1967. p. 161-170.

D'INTRONO, F.; TESO, E.; WESTON, R. Fonética y fonología actual del español. $2^{\text {a }}$ Ed. Madrid: Cátedra, 2010.

DERWING, T. M.; MUNRO, M. J. Second language accent and pronunciation teaching: a research-based approach. TESOL Quarterly, v. 39, n. 3, 2005, p. 379-397.

ELLIS, N. Selective attention and transfer phenomena in SLA: contingency, cue competition, salience, interference, overshadowing, blocking, and perceptual learning. Applied Linguistics, v.27. 2006.

ELLIS, N. The dynamics of second language emergence: cycles of language use, language change, and language acquisition. The Modern Language Journal, v. 92, n. 2, 2008. p. 232-249.

FLEGE, J. E. Second language speech learning: theory, findings, and problems. In: STRANGE, W. (Ed.), Speech perception and linguistic experience: issues in cross-language research. Timonium, MD: York Press, 1995. p. 233-277.

HUALDE, J. I. Los sonidos del español. Nova Iorque: Cambridge University Press, 2014.

LADO, R. Linguistics across cultures. Ann Arbor: University of Michigan Press, 1957.

LARSEN-FREEMAN, D. A complexity theory approach to second language development/acquisition. In: ATKINSON, D. Alternative approaches to second language acquisition. New York: Routledge, 2011.

LARSEN-FREEMAN, D. Chaos/complexity science and second language acquisition. Applied Linguistics, v. 18, n.2, 1997. p.141-165.

MONTES GIRALDO, J. J. El español de Colombia: propuesta de clasificación dialectal. In: Thesaurus - Boletín del Instituto Caro y Cuervo, tomo XXXVII, n. 1, 1982. p.23-92.

OLIVEIRA, R.A. A influência da instrução fonética explícita na produção e na percepção dos fricativos sonoros por hispanofalantes aprendizes de português como língua estrangeira - PLE. 163f. Dissertação (Mestrado em Letras), Recife, Universidade Federal de Pernambuco, 2016. 
ROHENA-MADRAZO, M. Diagnosing the completion of a sound change: phonetic and phonological evidence for $/ \mathrm{f} /$ in Buenos Aires Spanish. Language Variation and Change, v. 27, 3, 2015.

SELINKER, L.; LAMENDELLA, J.T. Two Perspectives on Fossilization in Interlanguage Learning. Interlanguage Studies Bulletin, 3(2), 1978.

SILVA, A. H. P. Towards a dynamic view on L2 phonological acquisition. In: International Symposium on the Acquisition of Second Language Speech New Sounds, 5, 2007, Florianopolis, Brazil. RAUBER, A. S.; WATKINS, M. A.; BAPTISTA, B. O. (Orgs.). New Sounds 2007: Proceedings of the Fifth International Symposium on the Acquisition of Second Language Speech, 2008. p. 448-458.

SILVEIRA, R.; ROSSI, A. Ensino da pronúncia de português como segunda língua: considerações sobre materiais didáticos. Revista Virtual de Estudos da Linguagem - ReVEL, v, 4, n. 7, 2006.

SMITH, C. L. The devoicing in /z/ in American English: effects of local and prosodic context. Journal of Phonetics, 25, 1997. p. 471-500.

STEIN, C. C. O conhecimento fonético acústico-articulatório e o ensino de língua estrangeira. Signum: Estudos da Linguagem, Londrina, n. 14/2, 2011. p. 355374.

VERSPOOR, M. LOWIE, W.; DE BOT, K. Input and Second Language Development from a Dynamic Perspective. In: PISKE, T; YOUNG-SCHOLTEN. Input Matters in SLA. Bristol: Multilingual Matters, 2007.

\section{NOTAS}

$1 \mathrm{O}$ termo "estratégia de pronúncia", a nosso ver, parece refletir melhor o processo de adaptação acústico-perceptivo e articulatório da L2, isto é, reflete melhor um sistema adaptativo, ao contrário do termo "erro de pronúncia" ou "transferência/ interferência", que parece sugerir a previsibilidade e estabilidade de um processo que é, por excelência, complexo e não linear.

${ }^{2}$ Larsen-Freeman (2011) sugere o termo "desenvolvimento" como mais adequado quando se trata de sistemas abertos, uma vez que tais sistemas nunca são totalmente adquiridos. Logo, o termo "aquisição", para a autora, remete a sistemas estáticos.

${ }^{3} \mathrm{O}$ termo aprendizado é o preferido por Ellis, assim como o termo desenvol- 
vimento é preterido por Larsen-Freeman. Neste trabalho, não faremos distinção entre os termos "aprendizado", "desenvolvimento" e "aquisição".

${ }^{4}$ É válido mencionar que as palavras ou frases utilizadas nos exercícios práticos não eram as mesmas apresentadas no momento da leitura das frases elaboradas para o teste de produção da pesquisa.

${ }^{5}$ Os dados referentes ao desvozeamento são indicados pelo diacrítico proposto pela Associação Internacional de Fonética - IPA. Aqui, sempre que utilizarmos o diacrítico $\left[^{\circ}\right]$, faremos menção a um processo de desvozeamento parcial. Por outro lado, sempre que utilizarmos de um som fricativo desvozeado, referimo-nos a um processo de desvozeamento total, no qual não houve o emprego de vozeamento em uma consoante genuinamente vozeada. O desvozeamento parcial, como será visto, caracteriza-se com uma tentativa legítima de emprego de vozeamento, interpretado aqui como um processo dinâmico. A depender do contexto, a substituição de um som vozeado por um desvozeado também pode ser considerada como um processo dinâmico, desde que claramente fora de situações previsíveis.

${ }^{6}$ Atualmente, principalmente na fala dos jovens bonaerenses, existe a tendência ao šeísmo, que consiste na mudança paulatina de [3] para [S] (cf. HUALDE, 2014; ROHENA-MADRAZO, 2015).

${ }^{7}$ Hualde (2014) indica que, a depender do dialeto hispânico, [j] pode ser classificado foneticamente a partir do grau de abertura empregado em sua produção. Quando a abertura for maior (sem fricção audível), classifica-se como aproximante; quando a abertura for menor, o fone é classificado como fricativo.

Recebido: 22/04/2018

Aceito: 14/09/2018 